\title{
Subcutaneous Infusion and Capillary "Finger Stick" Sampling of Stable Isotope Tracer in Metabolic Studies
}

\author{
PAULA M. HERTEL, SHAJI K. CHACKO, SUNITA PAL, AGNETA L. SUNEHAG, AND MOREY W. HAYMOND \\ Department of Pediatrics, Children's Nutrition Research Center, U.S. Department of Agriculture/Agricultural Research Service, Baylor \\ College of Medicine, Houston, Texas, 77030
}

\begin{abstract}
Metabolic studies utilizing stable isotope tracer in humans have typically used intravenous tracer infusions and venous blood sampling. These studies explore subcutaneous infusion of isotope and "finger stick" capillary blood sampling to measure glucose turnover. Five subjects received simultaneous 8-h infusions of glucose labeled with isotope: $\left[1-{ }^{13} \mathrm{C}\right]$ glucose subcutaneously and $\left[6,6-{ }^{2} \mathrm{H}_{2}\right]$ glucose intravenously. At regular intervals, venous and finger stick blood specimens were obtained. Finger stick blood was applied to filter paper. Substrate and isotopic steady state was reached after $7.0 \mathrm{~h}$ with both routes of infusion. The isotopic enrichments of finger stick and venous specimens did not differ significantly for the subcutaneously infused $\left[1-{ }^{13} \mathrm{C}\right]$ glucose $(p=0.33$ and $p=0.23$, respectively) but the finger stick $\left[6,6-{ }^{2} \mathrm{H}_{2}\right]$ glucose enrichment was slightly higher $(p<0.03)$ than that of the venous sample. Using $\left[6,6-{ }^{2} \mathrm{H}_{2}\right]$ glucose infusion and venous plasma sampling as the reference method, the $\left[1-{ }^{13} \mathrm{C}\right]$ glucose gave estimates of glucose $R_{a}$ that were $13 \%$ (plasma) and 17\% (finger stick) lower ( $p<0.001$ and $p<$ 0.02 , respectively). This difference could be attributed to recycling of ${ }^{13} \mathrm{C}$ label. In conclusion, subcutaneous infusion and finger stick specimen collection onto filter paper represent a potential method of conducting in vivo studies of substrate metabolism outside of a hospital-based research unit. (Pediatr Res 60: 597-601, 2006)
\end{abstract}

$\mathrm{T}_{\mathrm{r}+\mathrm{s}}$ raditionally, isotope dilution kinetic studies of glucose, FFA, and amino acid metabolism in humans have primarily used intravenous infusion (and oral administration when tracing enteral absorption) of compounds labeled with stable isotopes and measurement of substrate enrichment in venous blood (1,2). Intravenous infusion and sampling enables rapid and direct introduction of labeled substrate into the intravascular mixing pool and easy blood sampling. Intravenous access, however, requires that subjects be studied in an inpatient or outpatient clinical research setting to monitor and manage the intravenous infusion and sampling sites. Additionally,

Received February 22, 2006; accepted June 8, 2006.

Correspondence: Morey W. Haymond, M.D., USDA/ARS Children's Nutrition Research Center, 1100 Bates Street, Houston, TX 77030-2600; e-mail: mhaymond @ bcm.tmc.edu

These studies were supported in part by grants from the Children's Nutrition Research Center (USDA/ARS Cooperative Agreement 58-625-6-001) and the National Institutes of Health (RO1 DK55478 and RO1 HD37957).

This work is a publication of the U.S. Department of Agriculture/Agricultural Research Service, Children's Nutrition Research Center, Department of Pediatrics, Baylor College of Medicine, Houston, TX. The contents of this publication do not necessarily reflect the views or policies of the U.S. Department of Agriculture, and mention of trade names, commercial products, or organizations does not imply endorsement from the U.S. government.

DOI: $10.1203 / 01 . p d r .0000242267 .47282 .29$ such study conditions dramatically decrease the subject's normal activity during the period of study.

The purpose of this study was to evaluate the validity of the use of subcutaneous infusion of tracer and a "finger stick" blood sampling method to measure glucose kinetics by comparing these results with data obtained using a simultaneous intravenous infusion and blood sampling of a second glucose tracer, the current "gold standard" for this type of study. Were such a model using subcutaneous infusion and finger stick sampling successful, it would provide a methodology to study substrate kinetics outside of the metabolic research unit under more real-life conditions.

\section{METHODS}

Subjects. The protocol was reviewed and approved by the Institutional Review Board for Human Subject Research at Baylor College of Medicine in Houston, TX. Twelve healthy subjects, five females and seven males, were recruited by newspaper advertisement or by word of mouth. The mean subject age was $25.1 \pm 1.2 \mathrm{y}$ and mean body mass index was $22.9 \pm 0.8 \mathrm{~kg} / \mathrm{m}^{2}$. All subjects were healthy and had a normal physical examination and screening laboratory studies, including $\mathrm{Hb}$ and chemistry panel, and, in all women, a negative pregnancy test. Written consent was obtained at the screening visit or on study day before beginning the protocol.

Tracers. Sterile and pyrogen-free $\left[6,6-{ }^{2} \mathrm{H}_{2}\right]$ glucose $\left(99\right.$ atom $\left.\%{ }^{2} \mathrm{H}\right)$ and $\left[1-{ }^{13} \mathrm{C}\right]$ glucose $\left(99\right.$ atom $\left.\%{ }^{13} \mathrm{C}\right)$ were purchased from Cambridge Isotope Laboratories (Andover, MA). The stable isotopes were retested for sterility and pyrogenicity by the Investigational Pharmacy at Texas Children's Hospital. For each subject, $\left[6,6-{ }^{2} \mathrm{H}_{2}\right]$ glucose was mixed with sterile $0.9 \%$ saline to deliver isotope at a rate of $0.04 \mathrm{mg} / \mathrm{kg} \cdot \min \left(0.22 \mu \mathrm{mol} \cdot \mathrm{kg}^{-1} \cdot \mathrm{min}^{-1}\right)$. $\left[1{ }^{13} \mathrm{C}\right]$ glucose was mixed with sterile water to a concentration of $10 \%$. The glucose concentration of all infusates was verified using a glucose oxidase method (YSI glucose analyzer; YSI Inc., Yellow Springs, OH). The stable isotope solutions for intravenous or subcutaneous infusion were prepared using sterile technique, following which they were filtered $(0.01 \mu \mathrm{m}$, Millipore Corporation, Inc. Bedford, MA), stored in sterile syringes, and kept refrigerated at $4^{\circ} \mathrm{C}$ until used within $36 \mathrm{~h}$ of preparation.

Subcutaneous infusion pumps. The $\left[1-{ }^{13} \mathrm{C}\right]$ glucose tracer was infused subcutaneously using MiniMed 508 insulin pumps (MiniMed, Sylmar, CA) with sterile, disposable MiniMed Sof-set infusion sets consisting of a syringe connection hub, tubing, and a $1-\mathrm{cm}$ subcutaneous infusion delivery needle, and sterile, disposable 3.0-mL MiniMed reservoirs.

Glucose extraction from filter paper. Before performing studies on human subjects, we tested a number of extraction techniques from Whatman filter paper of $\left[1-{ }^{13} \mathrm{C}\right]$ glucose-spiked blood samples. Filter paper was prepared with $2.5 \% \mathrm{NaF}$ solution as described below. Heparinized blood with a $7 \%$ $\left[1-{ }^{13} \mathrm{C}\right]$ glucose enrichment was dropped on Whatman paper previously treated with $\mathrm{NaF}$ as well as on untreated paper. The specimens were allowed to dry and then processed and derivatized as described below.

NaF-treated Whatman filter paper. Whatman $7.0-\mathrm{cm}$ type 1 filter papers were obtained from Sigma Chemical Co. (St. Louis, MO) and sodium fluoride

Abbreviations: GC-C-IRMS, gas chromatography-combustion-isotope ratio mass spectrometry; GC/MS, gas chromatography/mass spectometry 
powder $(\mathrm{NaF}), 99.1 \%$ pure, obtained from J.T. Baker (Phillipsburg, NJ). The filter papers were dipped into a $2.5 \% \mathrm{NaF}$ (wt/vol) solution mixed with Millipore-filtered water and allowed to air-dry overnight on a clean surface. The NaF inhibits glycolysis in blood cells and preserves the glucose collected on the filter paper during drying and sample preparation. A $\mathrm{NaF}$ concentration of $2.5 \%$ was chosen because it is comparable to the $\mathrm{NaF}$ concentration attained when blood specimens (of specified volume as indicated by manufacturer) are placed in commercially sold NaF-containing blood specimen tubes. Differences in enrichments between the specimens placed on NaFtreated as compared with untreated paper were not significant, but the amount of ethyl acetate required to dilute the derivatized specimens before the GC/MS procedure was significantly greater for the specimens extracted from the NaF-containing filter paper $(p=0.04)$ than for those extracted from the plain filter paper, indicating that a greater amount of substrate was extracted from these papers. We did not find a significant difference in extractability of $\left[1-{ }^{13} \mathrm{C}\right]$ glucose from Whatman paper types $1,4,5$, and 42 .

In the first seven subjects studied, we sought to determine both the sensitivity and reproducibility to carry out a subcutaneous infusion/sampling method. In all of the early subjects, we observed one or more values from the finger stick samples that clearly reflected contamination (Fig. 1). Many, but not all, of these spikes were noted (data not shown) at times corresponding to discontinuation of the isotope infusions and removal of isotope infusion line at the 8-h time point, suggesting investigator-induced contamination. Subsequently, measures were taken to prevent contamination, including: cleaning of the paper puncher between specimens with ethyl acetate, assaying prepared filter paper samples for isotope before using them on study day (to verify no contamination was present), and preparing the filter papers using a very stringent "clean" technique. This "clean" technique included frequent glove changes during the preparation of the paper when the glove may come into contact with other objects, drying filter paper on clean, disposable laboratory paper in areas where isotopes are not used, and taking great care on study days to keep filter papers out of contact with any surfaces. Finally, we observed a dramatic reduction in contamination after the filter papers were enveloped in laminated paper sheaths after initial drying and using warm-water soaks of subjects' hands before performing each finger stick. The traditional method of conducting in vivo stable isotope studies employs intravenous isotope infusion of $\left[6,6-{ }^{2} \mathrm{H}_{2}\right]$ glucose and blood sampling from the contralateral arm. Because $\left[6,6-{ }^{2} \mathrm{H}_{2}\right]$ glucose trace is not recycled back into the sampling space (1-3), it is considered to be the most valid tracer for calculating total glucose $R_{a}$. Therefore, $\left[6,6-{ }^{2} \mathrm{H}_{2}\right]$ glucose plasma enrichments were the "gold standard" to which the results of the new methods were compared.

Study design and protocol. Subjects were instructed to consume a normal diet during the $3 \mathrm{~d}$ preceding the study day, to ingest only water beginning at midnight the night before the study ( $8 \mathrm{~h}$ before beginning of study period), and to remain in the fasted state until completion of the study.

On the morning of the study day, subjects arrived in the Metabolic Research Unit (MRU) at the Children's Nutrition Research Center, Houston, TX, by $0700 \mathrm{~h}$. Two antecubital intravenous catheters were placed: one for infusion of $\left[6,6-{ }^{2} \mathrm{H}_{2}\right]$ glucose and one in the contralateral arm for venous blood sampling. Baseline venous and finger stick blood samples were obtained, and the MiniMed pump was set up for infusion according to the product manual for insulin infusion. Briefly, a Sof-set needle was used in the skin of the lateral part of the abdomen. Subjects remained in bed for the duration of the 11-h study period. Most subjects briefly left the bed to use the nearby bathroom once or twice during the study period, during which time special care was taken to assure continuous isotope infusion.

After baseline blood sampling, isotope infusions were initiated. Continuous infusion of $\left[6,6-{ }^{2} \mathrm{H}_{2}\right]$ glucose (Razel Syringe Pump, Razel Scientific Instruments Inc., Stamford, CT) at a rate of $0.2 \mu \mathrm{mol} / \mathrm{kg} / \mathrm{min}(0.0364$ $\left.\mathrm{mg} \cdot \mathrm{kg}^{-1} \cdot \mathrm{min}^{-1}\right)$ was "piggy backed" into $0.45 \%$ saline infusion $(20 \mathrm{~mL} / \mathrm{h})$. At the same time, a $10 \%\left[1{ }^{13} \mathrm{C}\right]$ glucose was infused subcutaneously at a rate of $350 \mu \mathrm{L} / \mathrm{h}$, which averaged $0.045 \mu \mathrm{mol} / \mathrm{kg} / \mathrm{min}\left(0.009 \mathrm{mg} \cdot \mathrm{kg}^{-1} \cdot \mathrm{min}^{-1}\right)$ for the five subjects used in the final analyses. Both isotopes were infused for $8 \mathrm{~h}$. At the end of the $8 \mathrm{~h}$ of isotope infusion, both infusions were discontinued and infusion needles immediately removed to avoid any further entry of isotope into the tissues during the isotope decay portion of the study. Blood sampling was continued for an additional 3-h isotope decay period.

Both finger stick and venous blood were obtained at $0 \mathrm{~h}$ (immediately before starting infusions), $1 \mathrm{~h}, 2 \mathrm{~h}, 3 \mathrm{~h}, 4 \mathrm{~h}, 5 \mathrm{~h}, 6 \mathrm{~h}, 6 \mathrm{~h} 30 \mathrm{~min}, 7 \mathrm{~h}, 7 \mathrm{~h} 30$ min, 8 h, 8 h $30 \mathrm{~min}, 9 \mathrm{~h}, 9 \mathrm{~h} 30 \mathrm{~min}, 10 \mathrm{~h}, 10 \mathrm{~h} 30 \mathrm{~min}$, and $11 \mathrm{~h}$. Our subjects tolerated the repetitive finger sticks without difficulty. A several-minute hand soak in fresh warm water in some subjects facilitated blood flow and obviated a need for a second stick. Two of our 12 subjects expressed mild discomfort with the finger sticks toward the end of the study period. Thus, in prolonged studies with repetitive finger sticks, it may be worthwhile to consider a topical anesthetic such as Emla cream to reduce discomfort.

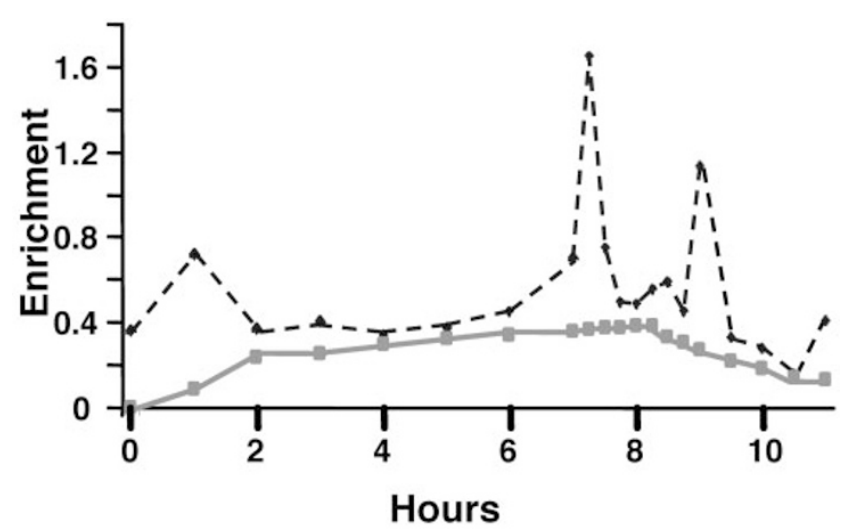

Figure 1. Contaminated finger stick glucose enrichments. This figure depicts the enrichment in finger stick and venous specimens from a single subject receiving a subcutaneous infusion of $\left[1-{ }^{13} \mathrm{C}\right]$ glucose and demonstrates the obvious contamination of the finger stick samples. $\left[1{ }^{13}\right] \mathrm{C}$ glucose venous (ם), $\left[1{ }^{13}\right] \mathrm{C}$ glucose fingersticks $(\bullet)$.

Venous blood specimens ( $5 \mathrm{~mL}$ each) were placed immediately into EDTA tubes, placed on ice, and centrifuged $\left(3000 \mathrm{rpm}\right.$ for $10 \mathrm{~min}$ at $\left.4^{\circ} \mathrm{C}\right)$. The plasma was separated and stored at $-70^{\circ} \mathrm{C}$ before analysis. Finger sampling sites were prepared by soaking the subject's hand in fresh, lukewarm tap water (3-5 min) and dried with a clean paper towel. The fingertip was then gently scrubbed with isopropyl alcohol and pricked with a standard disposable lancet device, as is used for self- monitoring of glucose. Blood was dropped onto NaF-impregnated filter paper (see above) of a quantity sufficient to saturate an area approximately $2 \mathrm{~cm}$ in diameter. The filter papers were enclosed and allowed to dry thoroughly (for a minimum of $20 \mathrm{~min}$ ).

Sample preparation. Plasma samples were prepared as described above and analyzed as described below. A conventional, hand-held office paper puncher with the plastic reservoir removed was used to punch four $6.5-\mathrm{mm}$ circles from each finger stick specimen. The paper puncher was cleaned with an ethyl acetate-saturated cotton swab between specimens to avoid crosscontamination of isotope from one specimen to the next. Using latex gloves, each set of four hole-punches was placed into a plastic microcentrifuge tube for storage at $-70^{\circ} \mathrm{C}$ until analyzed.

Analyses. One hundred and fifty microliters of sterile deionized water was placed into each tube containing a filter paper blood specimen. The tubes were refrigerated at $4^{\circ} \mathrm{C}$ for $1 \mathrm{~h}$, then briefly vortexed. The water solution was transferred into $1.5-\mathrm{mL}$ microcentrifuge tubes. Two hundred microliters of ice-cold acetone was added to deproteinize the sample, and each tube was briefly vortexed and capped before being refrigerated again for $10 \mathrm{~min}$. Specimens were centrifuged $\left(3000 \mathrm{rpm}\right.$ at $\left.4^{\circ} \mathrm{C}\right)$ for $10 \mathrm{~min}$, and the supernatant decanted into $4-\mathrm{mL}$ vials and evaporated completely under nitrogen gas. Fifty microliters acetic anhydride:pyridine (2:1) was added to each tube. The tubes were sealed tightly with a Teflon-faced cap, vortexed briefly, and heated at $60^{\circ} \mathrm{C}$ for $10 \mathrm{~min}$. The contents were then dried under nitrogen gas and subsequently reconstituted in $30 \mu \mathrm{L}$ ethyl acetate.

The enrichment of $\left[6,6-{ }^{2} \mathrm{H}_{2}\right.$ ]glucose was measured by GC/MS [Agilent Technologies (Palo Alto, CA) 6890/5973 GC/MS; GC column, SPB-1701: 30 $\mathrm{m} \times 0.25 \mu \mathrm{m} \times 0.25 \mu \mathrm{m}$; Supelco, Bellefonte, PA), using the electron impact mode with selective monitoring of $\mathrm{m} / \mathrm{z} 242$, unlabeled glucose, and 244 , $\left[6,6-{ }^{2} \mathrm{H}_{2}\right]$ glucose. Enrichments of $\geq 0.7 \%$ are detectable using this method, with a coefficient of variation (CV) of 1-3\% on samples with enrichments $\geq 1 \%$. The $\left[1-{ }^{13} \mathrm{C}\right]$ glucose enrichment was determined with GC-C-IRMS (Thermo Finnigan Delta ${ }^{\text {plus }}$ XL GC-C-IRMS; Thermo Electron Corp., Waltham, MA) coupled with a 6890 GC (Agilent Technologies). GC-C-IRMS measures the ${ }^{13} \mathrm{CO}_{2} /{ }^{12} \mathrm{CO}_{2}$ ratio, thus excluding any interference from the $\left[6,6-{ }^{2} \mathrm{H}_{2}\right]$ glucose. Enrichments $<0.1 \%$ are detectable using this method, with a CV of $0.3 \%$ on samples with enrichments of $0.3-0.9 \%$.

Enrichment data were separated into four groups based on infusion route and sampling method: 1) $\left[6,6-{ }^{2} \mathrm{H}_{2}\right]$ glucose finger stick, 2) $\left[6,6-{ }^{2} \mathrm{H}_{2}\right]$ glucose venous, 3$)\left[1-{ }^{13} \mathrm{C}\right]$ glucose finger stick, and 4$)\left[1-{ }^{13} \mathrm{C}\right]$ glucose venous. Steady state was achieved between study hours 7.0 and 8.0. Steady state enrichments were calculated for each subject by averaging enrichments from time points $7 \mathrm{~h}, 7.5 \mathrm{~h}$, and $8 \mathrm{~h}$, and mean steady state enrichments for all subjects within each of the four groups were determined based on these values.

Calculations. Steady state was defined by CV $<10 \%$ and curve slope not significantly different from zero during the 7th hour of isotope infusion. CV was calculated for each subject for each isotope/sampling method (four CV 
calculations per subject) using the enrichments of samples taken at $7 \mathrm{~h}, 7.5 \mathrm{~h}$, and $8 \mathrm{~h}$ using the following equation:

\section{$\mathrm{CV}=\mathrm{SD}$ of enrichments/mean of enrichments}

Mean CV was then determined for each isotope for each blood sampling method (four data groups). Slopes during the 7th hour of infusion were also calculated using a regression plot (Microsoft Excel v. 9.0.2720; Microsoft, Redmond, WA), and $t$ test (see "Statistics") was used to determine whether slopes were significantly different from zero. Rate of appearance $\left(R_{a}\right)$ of glucose was calculated using enrichments of each of the tracers ([6,6$\left.{ }^{2} \mathrm{H}_{2}\right]$ glucose and $\left[1{ }^{13} \mathrm{C}\right]$ glucose) in specimens obtained by each sampling method based on mean steady state enrichments using the following formula (3):

$$
\text { Glucose } R_{a}=\left[\left(E_{i} / E_{p}\right)-1\right] \times I
$$

where $E_{i}$ is the enrichment of the infusate $\left(99 \%\right.$ for $\left[1-{ }^{13} \mathrm{C}\right]$ glucose and $98 \%$ for $\left[6,6-{ }^{2} \mathrm{H}_{2}\right]$ glucose $), E_{p}$ is the enrichment of the tracer in plasma, and $I$ is the infusion rate of the tracer $(\mu \mathrm{mol} / \mathrm{kg} / \mathrm{min})$.

To compare graphically the rise and fall of the plasma enrichments of the two isotopes, enrichments at each time point for each subject were converted to percentage of the calculated mean steady state enrichment. Tracer half-life $\left(T_{1 / 2}\right)$ was calculated using standard formulas from $8 \mathrm{~h}$ to $11 \mathrm{~h}(4)$, based on ln of $\%$ mean steady state enrichments. Regression analysis was used to calculate the rate constant, which was defined as the slope of the decay curve converted to a linear format by using $\ln$ of each enrichment value. The half-life was calculated using the following formula derived as shown, where $k=$ rate constant (in hours)

$$
T_{1 / 2}=\ln 2 / k=0.693 / k
$$

Statistics. All comparisons were made assuming that the traditional intravenous infusion of $\left[6,6-{ }^{2} \mathrm{H}_{2}\right]$ glucose and venous sampling is the correct value for glucose turnover. This is based on the facts that all labels in [6,6${ }^{2} \mathrm{H}_{2}$ ] glucose are lost during glycolysis and/or gluconeogenesis and as such do not re-enter the circulation (recycle) (1-3). Paired $t$ tests were used to evaluate the new methods of infusion/sampling by comparing mean steady state enrichments, mean rates of appearance $\left(R_{a}\right)$, mean half-lives for decay curves, and the difference between steady state slopes (mean enrichments at sample times $7 \mathrm{~h}, 7.5 \mathrm{~h}$, and $8 \mathrm{~h}$ ) and a line with slope zero. A value of $p \leq 0.05$ was considered to indicate statistical significance. Bland-Altman analysis was used to compare methods based on mean $R_{a}$. All statistical analyses were performed on a personal computer using Microsoft Excel 2000 (v. 9.0.2720).

\section{RESULTS}

Following refinement of the technical aspect of this technique, we studied five subjects. Average enrichments are plotted for each isotope with each blood sampling method ([6,6- $\left.{ }^{2} \mathrm{H}_{2}\right]$ glucose finger stick, $\left[6,6-{ }^{2} \mathrm{H}_{2}\right]$ glucose venous, $\left[1-{ }^{13} \mathrm{C}\right]$ glucose finger stick, and $\left[1-{ }^{13} \mathrm{C}\right]$ glucose venous).

Plasma enrichments expressed as percentage steady state enrichment values are plotted based on the infused isotope (i.e. intravenous $\left[6,6-{ }^{2} \mathrm{H}_{2}\right]$ glucose versus subcutaneous $\left[1-{ }^{13} \mathrm{C}\right]$ glucose) and blood sampling method (i.e. venous versus finger stick blood sampling) (Fig. 2).

Plasma and finger stick blood glucose enrichments of the intravenous and subcutaneous infused isotopes both reach a steady state plateau by $6-7 \mathrm{~h}$ (Fig. 2). The rate of rise and fall (of percentage steady state enrichment) of tracer infused subcutaneously $\left(\left[1-{ }^{13} \mathrm{C}\right]\right.$ glucose $)$ was slower than for tracer infused intravenously $\left(\left[6,6-{ }^{2} \mathrm{H}_{2}\right]\right.$ glucose $)$, but steady state was still achieved by $7 \mathrm{~h}$ for both. The CV was $\leq 4.3 \%$ for all curves shown in Figure 2, and slopes during this time interval were not significantly different from zero for all four curves ( $p$ $\geq 0.07$ ), i.e. steady state was reached in all cases (Fig. 3).

Mean steady state enrichments of $\left[6,6-{ }^{2} \mathrm{H}_{2}\right]$ glucose were only slightly but significantly higher when measured using finger stick specimens than when measured using plasma
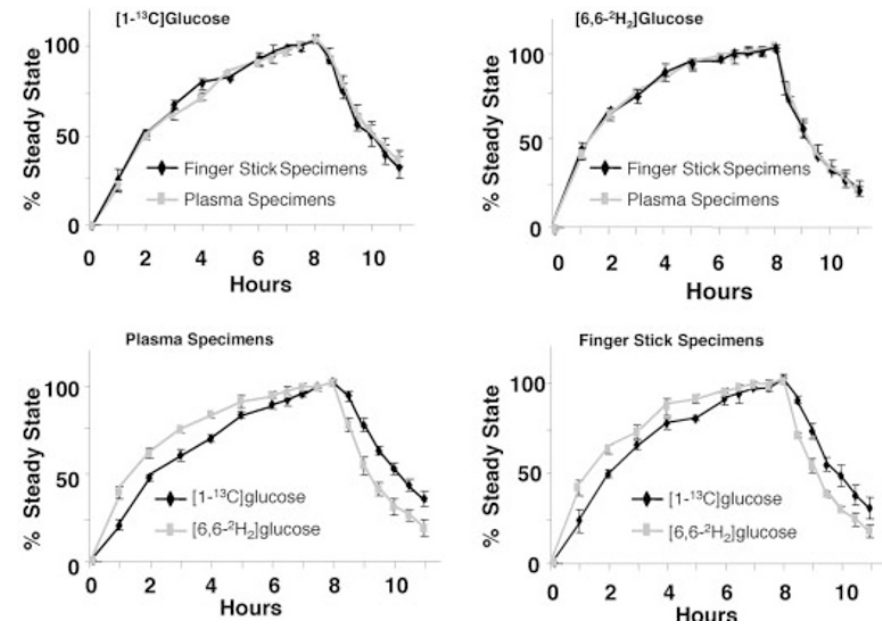

Figure 2. Plasma and finger stick glucose enrichment. Percentage steady state enrichments of finger stick and venous specimens plotted for subcutaneous infusate $\left(\left[1-{ }^{13} \mathrm{C}\right]\right.$ glucose $)$ and for intravenous infusate $([6,6-$ ${ }^{2} \mathrm{H}_{2}$ ]glucose). Rate of rise and fall of the enrichment of tracer infused subcutaneous $\left(\left[1-{ }^{13} \mathrm{C}\right]\right.$ glucose) was less rapid than for the tracer infused intravenous $\left(\left[6,6-{ }^{2} \mathrm{H}_{2}\right]\right.$ glucose $)$.

specimens $(2.15 \pm 0.10$ versus $2.08 \pm 0.14 \mathrm{~mol} \%$ enrichment, $p=0.03$ ). No significant difference between finger stick and plasma mean steady state enrichment of $\left[1-{ }^{13} \mathrm{C}\right]$ glucose was observed. (Table 1, Fig. 4).

Rates of appearance calculated based on the [6,6${ }^{2} \mathrm{H}_{2}$ ]glucose tracer and using finger stick versus plasma specimens were not significantly different. Similarly, no difference was observed in the rates of appearance of glucose using $\left[1-{ }^{13} \mathrm{C}\right]$ glucose based on finger stick versus plasma specimens. However, the rate of appearance of glucose using exclusively the venous plasma samples was $21 \%$ lower $(p<0.001)$ using the $\left[1-{ }^{13} \mathrm{C}\right]$ glucose compared with the $\left[6,6-{ }^{2} \mathrm{H}_{2}\right]$ glucose data. Rate of appearance of glucose using the $\left[1{ }^{13} \mathrm{C}\right]$ glucose was approximately $13 \%$ lower than $\left[6,6-{ }^{2} \mathrm{H}_{2}\right]$ glucose calculated based on finger stick specimens, but these values were not statistically different. There was a $17 \%$ difference $(p<0.02)$ in glucose $R_{a}$ when comparing the data derived from the $\left[6,6^{2} \mathrm{H}_{2}\right]$ glucose and intravenous sampling and that of $\left[1-{ }^{13} \mathrm{C}\right]$ glucose with finger stick blood (Table 1 ).

Rate of decay of each isotope in the blood did not differ significantly when calculated using finger stick versus plasma enrichments (Fig. 2, Table 2). Rate of decay of isotope appears to be slightly slower for $\left[1-{ }^{13} \mathrm{C}\right]$ glucose (subcutaneous admin-
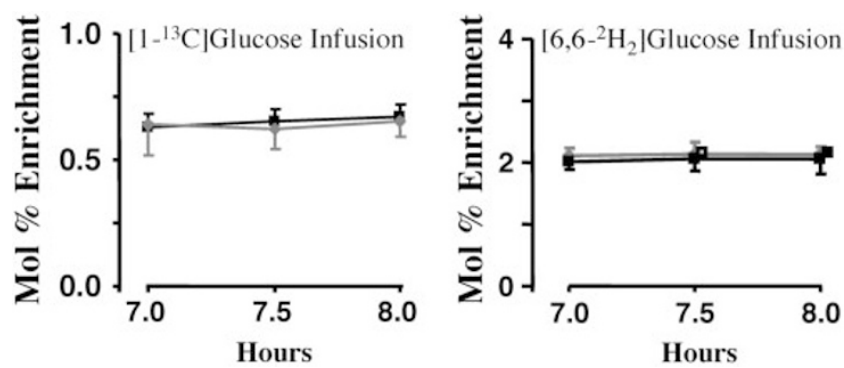

Figure 3. Steady state $\mathrm{CV}$ and slope. Enrichment curves during steady state $\left(7 \mathrm{~h}, 7.5 \mathrm{~h}, 8 \mathrm{~h}\right.$ ) for $\left[1{ }^{13} \mathrm{C}\right]$ glucose and $\left[6,6-{ }^{2} \mathrm{H}_{2}\right]$ glucose. $\mathrm{CV}$ is $\leq 4.3 \%$ for all curves, and slopes are not significantly different from zero. Finger stick $(\diamond)$, plasma (๑). 
Table 1. Rate of appearance of glucose

\begin{tabular}{|c|c|c|}
\hline & $\begin{array}{c}\text { Intravenous } \\
{\left[6,6-{ }^{2} \mathrm{H}_{2}\right] \text { glucose }}\end{array}$ & $\begin{array}{l}\text { Subcutaneous } \\
{\left[1-{ }^{13} \mathrm{C}\right] \text { glucose }}\end{array}$ \\
\hline $\begin{array}{l}\text { Isotope infusion rate } \\
\qquad(\mu \mathrm{mol} / \mathrm{kg} / \mathrm{min})\end{array}$ & $0.219 \pm 0.004$ & $0.054 \pm 0.006^{*}$ \\
\hline $\begin{array}{l}\text { Venous blood data } \\
(\mu \mathrm{mol} / \mathrm{kg} / \mathrm{min})\end{array}$ & $10.30 \pm 0.73 * * \S$ & $8.18 \pm 0.88^{* *} *$ \\
\hline $\begin{array}{l}\text { Finger stick blood data } \\
\qquad(\mu \mathrm{mol} / \mathrm{kg} / \mathrm{min})\end{array}$ & $9.89 \pm 0.58 \dagger$ & $8.59 \pm 1.11 \S \dagger$ \\
\hline \multicolumn{3}{|c|}{$\begin{array}{l}* \text { The absolute }\left[1-{ }^{13} \mathrm{C}\right] \text { glucose infusion rate was identical for each subject } \\
\text { ut, because the subjects weight was similar, the } \mathrm{SE} \text { is the result of the } \\
\text { ariance of the weights. } \\
* * p<0.001(21 \% \text { difference). } \\
\S p=0.02 \text { (17\% difference). } \\
\dagger p=0.102(13 \% \text { difference). }\end{array}$} \\
\hline
\end{tabular}

istration) than for $\left[6,6-{ }^{2} \mathrm{H}_{2}\right]$ glucose (intravenous administration), but half-life calculations are not significantly different (Fig. 2, Table 2).

Bland-Altman analysis of mean $R_{a}$ was carried out comparing the result of the conventional method of intravenous tracer infusion with venous blood specimens to those using subcutaneous tracer infusion with finger stick blood specimens. Differences in $R_{a}$ all fall within $1 \mathrm{SD}$ of the mean difference, with the exception of a single subject, for whom the difference in $R_{a}$ as determined by the different methods falls within 2 SD from the mean. Although a correct statistical technique, we recognize that the number of comparisons is very small.

\section{DISCUSSION}

The present data demonstrate the utility of subcutaneous infusions of stable isotope in humans subjects to estimate substrate flux when compared with the traditional intravenous tracer infusions. In addition, blood sampling via finger stick using NaF-impregnated filter paper is a suitable alternative to venous blood sampling.

Near steady state was achieved by $7 \mathrm{~h}$ for both infusion methods and using either blood sampling method. However, the intravenously infused tracer approaches steady state somewhat more rapidly than the subcutaneously administered tracer. Although the rate of decay was not significantly different between the two routes of tracer administration, regardless of the blood sampling site (venous versus finger stick blood), the decay of the intravenously administered [6,6${ }^{2} \mathrm{H}_{2}$ ]glucose appeared more rapid. A larger sample size might demonstrate a significant difference.


Figure 4. Steady state enrichments and turnover rates. Mean steady state enrichments and rates of appearance for $\left[1-{ }^{13} \mathrm{C}\right]$ glucose and $[6,6-$ ${ }^{2} \mathrm{H}_{2}$ ]glucose. Comparison of results obtained with each sampling method. Finger stick ( $\mathbb{Q}$ ), plasma ( $\square$ ).
Table 2. Mean decay half-life ( $T_{1 / 2}$ in hours)

\begin{tabular}{lccc}
\hline & Plasma & Fingerstick & $p$ Value \\
\hline $\begin{array}{ccc}{\left[1-{ }^{13} \mathrm{C}\right] \text { glucose }} \\
\text { (subcutaneous infusion) }\end{array}$ & $2.50 \pm 0.89$ & $1.89 \pm 0.79$ & 0.34 \\
$\begin{array}{l}{\left[6,6-{ }^{2} \mathrm{H}_{2}\right] \text { glucose }} \\
\text { (intravenous infusion) }\end{array}$ & $1.40 \pm 0.39$ & $1.37 \pm 0.40$ & 0.80 \\
$p$ Value & 0.14 & 0.38 & \\
\hline
\end{tabular}

Fingerstick $\left[1-{ }^{13} \mathrm{C}\right]$ glucose $v$ s plasma $\left[6,6-{ }^{2} \mathrm{H}_{2}\right]$ glucose $\mathrm{T}_{1 / 2}: p=0.37$.

Half-life $\left(\mathrm{T}_{1 / 2}\right)$ calculations: $\left[6,6{ }^{2} \mathrm{H}_{2}\right]$ glucose (intravenous infusate) has a slightly shorter half-life than does $\left[1-{ }^{13} \mathrm{C}\right]$ glucose (subcutaneous infusate), but this does not reach statistical significance.

A significant difference in the rate of appearance of glucose was observed between the two isotopes used $\left(\left[1-{ }^{13} \mathrm{C}\right]\right.$ glucose and $\left[6,6-{ }^{2} \mathrm{H}_{2}\right]$ glucose). The rates of appearance using the $\left[1-{ }^{13} \mathrm{C}\right]$ glucose data were $17 \%$ lower (specifically, $13 \%$ lower by finger stick measurement and $21 \%$ lower by plasma measurement) than for $\left[6,6-{ }^{2} \mathrm{H}_{2}\right]$ glucose. An error in pump infusion rates was ruled out by verification of both the isotope concentration and the infusion rate in each study. Our finding of an approximately $17 \%$ difference in rates of appearance for $\left[1-{ }^{13} \mathrm{C}\right]$ glucose and $\left[6,6-{ }^{2} \mathrm{H}_{2}\right]$ glucose is in agreement with results reported by Tigas et al. (3). In their study, glucose $R_{a}$ was underestimated by $14 \%$ after a $14.5 \mathrm{~h}$ infusion of $\left[1-{ }^{13} \mathrm{C}\right]$ glucose. It is therefore reasonable to assume that this difference is secondary to reappearance of ${ }^{13} \mathrm{C}$ glucose into the circulation due to recycling of tracer, presumably via the Cori cycle (3). The slight delay in decay of $\left[1-{ }^{13} \mathrm{C}\right]$ glucose compared with $\left[6,6-{ }^{2} \mathrm{H}_{2}\right]$ glucose might also be explained by recycling of tracer via the Cori cycle, although a continued entry of subcutaneously infused tracer into the circulation via lymphatics even after the actual infusion has stopped might contribute.

Ideally, this study would have been designed such that half of our subjects received $\left[1-{ }^{13} \mathrm{C}\right]$ glucose subcutaneously and $\left[6,6-{ }^{2} \mathrm{H}_{2}\right]$ glucose intravenously, and the other half with the reverse in site of isotope infusion $\left(\left[1-{ }^{13} \mathrm{C}\right]\right.$ glucose intravenously and $\left[6,6-{ }^{2} \mathrm{H}_{2}\right]$ glucose subcutaneously) as we have previously done (3). This was not possible in this study. The maximum infusion rate of the subcutaneous pump used was $0.35 \mathrm{~mL} / \mathrm{h}$, and we used a concentration of glucose of $10 \%$, maximizing the rate that could be achieved for the subcutaneous tracer to $35 \mathrm{mg} / \mathrm{h}$. Thus, we were limited by both maximal pump infusion rate and concern about tissue irritation, which might have occurred at glucose concentrations above $10 \%$. At this rate of isotope infusion, the levels of sensitivity and accuracy of measurements of $\left[6,6-{ }^{2} \mathrm{H}_{2}\right]$ glucose using GC/MS analysis would have precluded the use of this tracer for subcutaneous infusion. This is not the case for $\left[1-{ }^{13} \mathrm{C}\right]$ glucose, which can be easily analyzed with great precision and accuracy using GC-C-IRMS.

From a practical point of view, subcutaneous infusion of isotope is very easy to establish. Placement of the infusion device is done with minimal discomfort and does not limit mobility during the study. One potential limitation of using an insulin infusion pump for delivery is reservoir volume. In our Mini-Med pumps, reservoir volume was slightly greater than $3 \mathrm{~mL}$, which, in an adult subject, was sufficient for a maxi- 
mum of $9 \mathrm{~h}$ infusion. In smaller (pediatric) subjects, however, lower infusion rates could be used, still producing accurate estimates of enrichments while allowing for infusion times of up to, perhaps, $18-20 \mathrm{~h}$.

Using finger sticks for blood sampling and application of the sample to NaF-impregnated filter paper is also attractive for human studies. Our primary initial problem was identifying a methodology that avoids contamination of the sample, which we believe we have done. Thus, appropriate precautions must be taken in the preparation of the NaF-impregnated filter paper and the application of the sample to the filter paper must be contamination free. Presumably, if subjects were to be sent out of the unit for the study period (e.g. at home), simple hand-washing would make contamination less likely, as the home environment would not contain highly enriched isotope "fomites" that plagued our early efforts. In addition, the use of a paper cover for the filter paper, much in the same manner as a stool guaiac test, further avoids direct contact with the filter paper before analysis.

In summary, we have demonstrated both the utility and limitation of the use of subcutaneous isotope infusion and finger stick sampling. Utilizing this technique could open the opportunity to study subjects under far more natural circumstances of normal life than that provided in a metabolic research unit.

Acknowledgments. The authors thank E. O'Brian Smith for his greatly appreciated advice regarding our statistical analyses, Kathryn Louie for technical assistance, nurse coordinator Andrea Dotting-Jones, and the staff of the Metabolic Research Unit at the Children's Nutrition Research Center for assistance with the execution of these studies.

\section{REFERENCES}

1. Bier DM, Arnold KJ, Sherman WR, Holland WH, Holmes WF, Kipnis DM 1977 In-vivo measurement of glucose and alanine metabolism with stable isotopic tracers. Diabetes 26:1005-1015

2. Bier DM, Leake RD, Haymond MW, Arnold KJ, Gruenke LD, Sperling MA, Kipnis DM 1977 Measurement of "true" glucose production rates in infancy and childhood with 6,6-dideuteroglucose. Diabetes 26:1016-1023

3. Tigas SK, Sunehag AL, Haymond MW 2002 Impact of duration of infusion and choice of isotope label on isotope recycling in glucose homeostasis. Diabetes 51:3170-3175

4. Shipley RA, Clark RE 2005 Tracer Methods for In Vivo Kinetics: Theory and Applications. Academic Press, New York, pp 3-6 